\title{
Calculation of fire resistance of building structures in software packages
}

\author{
Ivan Dmitriev ${ }^{1}$, Vladimir Lyulikov ${ }^{1, *}$, Olga Bazhenova $^{2}$ and Dmitry Bayanov ${ }^{3}$ \\ ${ }^{1}$ Peter the Great St. Petersburg Polytechnic University, 29 Politechnicheskaya St., St. Petersburg, \\ 195251, Russia \\ ${ }^{2}$ Moscow State University of Civil Engineering, 26, Yaroslavskoye shosse, Moscow, 129337, Russia \\ ${ }^{3}$ Tyumen Industrial University, Volodarskogo str., 38, Tyumen, 625000, Russia
}

\begin{abstract}
In the article a review of modern software systems allowing calculating the distribution of temperature fields in a structure in time, without loading and with it (the fire resistance limit of structures) under conditions of a special fire load has been given. The algorithm of the finite element method is used for the calculations, on which each of the considered complexes is based. Specifically: Sofistik, Abaqus, Normcad, Ansys, Robot structure. Comparative analysis has been made from the point of view of intuitive user interface, the possibilities of modeling various conditions and fire regimes, tools for communication with other software complexes and the format of output of results. The results demonstrating the capabilities of the post-processor Sofistik have been presented.
\end{abstract}

\section{Introduction}

The number of accidents that can cause a fire is still quite large. In this regard, the tasks of improving calculation and analytical methods for determining the fire resistance of load-bearing building structures are actuated, including those used for the purpose of increasing the fire resistance limits by means of fire protection [1-3].

The definition of design fires is the starting point of fire safety engineering. Fire scenarios should be determined with caution in close cooperation between the client, designers and authorities [4-6]. Variety of fires must be considered depending on the use intended for the building. The standardization of fire loads is extremely important for contractor's operations around the world. This is also important in the development of software systems. The most important indicator of building structures is the fire- resistance rating - the ability of structures to limit the spread of fire, and also to maintain the required performance at high temperatures in a fire. In practice, the fire resistance limit is determined by fire tests. The essence of the methods consists in determining the time from the beginning of the thermal action on the structure, in accordance with this standard, before one or several successive states of fire resistance occur, taking into account the functional purpose of the structure. [7-8]. There are following main types of limiting states of building structures for fire resistance. Loss of load capacity is due to collapse of the

\footnotetext{
*Corresponding author: lulikv@yandex.ru
} 
structure or occurrence of ultimate deformations (R). Loss of integrity resulting from the formation of through cracks or openings in the structures through which combustion products or flame (E) penetrate to the unheated surface. Loss of heat-insulating ability due to temperature rise on the unheated surface of the structure to the limit values for the given design (I). Additional limiting structural states and criteria for their occurrence, if necessary, are established in standards for testing specific designs. In practice, there is insufficient support for research laboratories. At the same time, full-scale tests are laborious and expensive, so it makes sense to apply mathematical modeling methods that are improved with annually [9-10].

Some normative documents of the Russian Federation and the European Union [11 - 13] establish computational algorithms for such methods for steel and reinforced concrete, but all of them are based on crude mathematical models of rod mechanics and give large errors and therefore can not be used for the final certification of load-bearing reinforced concrete building structures for their fire resistance.

\section{Materials and Methods}

In the ABAQUS (American company Abaqus, Inc.) software for calculation of heat transfer, the abaqus-standart module is used to solve traditional finite element analysis problems. There is no dedicated module for calculating the fire resistance of structures. ABAQUS uses its own powerful preprocessor, which allows creating almost any elements that include different materials (Fig.1)

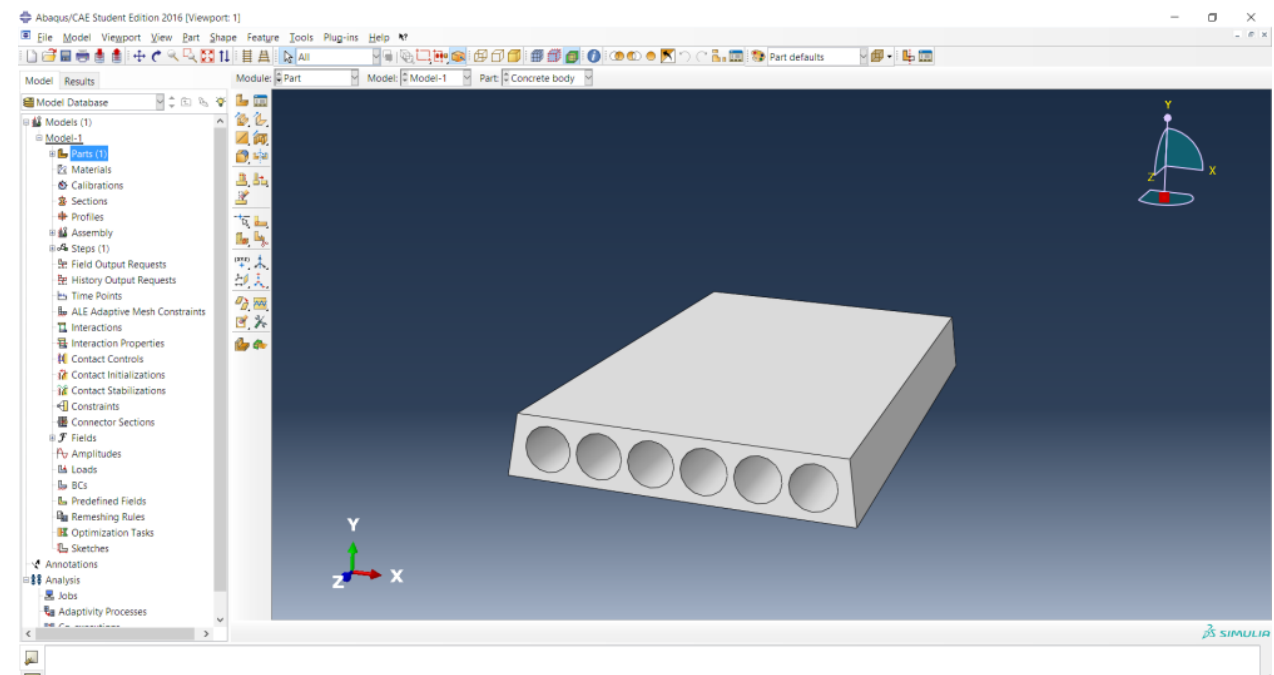

Fig. 1. 3D-model in ABAQUS

As a result of the calculation, the picture of VAT is determined at different stages of construction, as well as precipitation, deformation of the building elements. Almost any design can be simulated in its own preprocessor. But if we are talking about a typical element, which needs to specify the geometric parameters of the section and the material, in this case, this operation will take quite a lot of time. Typical materials are also absent, so for their formation, it is necessary to specify coefficients such as the modulus of elasticity, Poisson's ratio, and the coefficient of linear expansion (Fig.2). The software complex Ansys (American company Ansys, Inc.) is one of the most functional and advanced calculation programs. Calculation of fire resistance is carried out by the developers designated as temperature analysis 


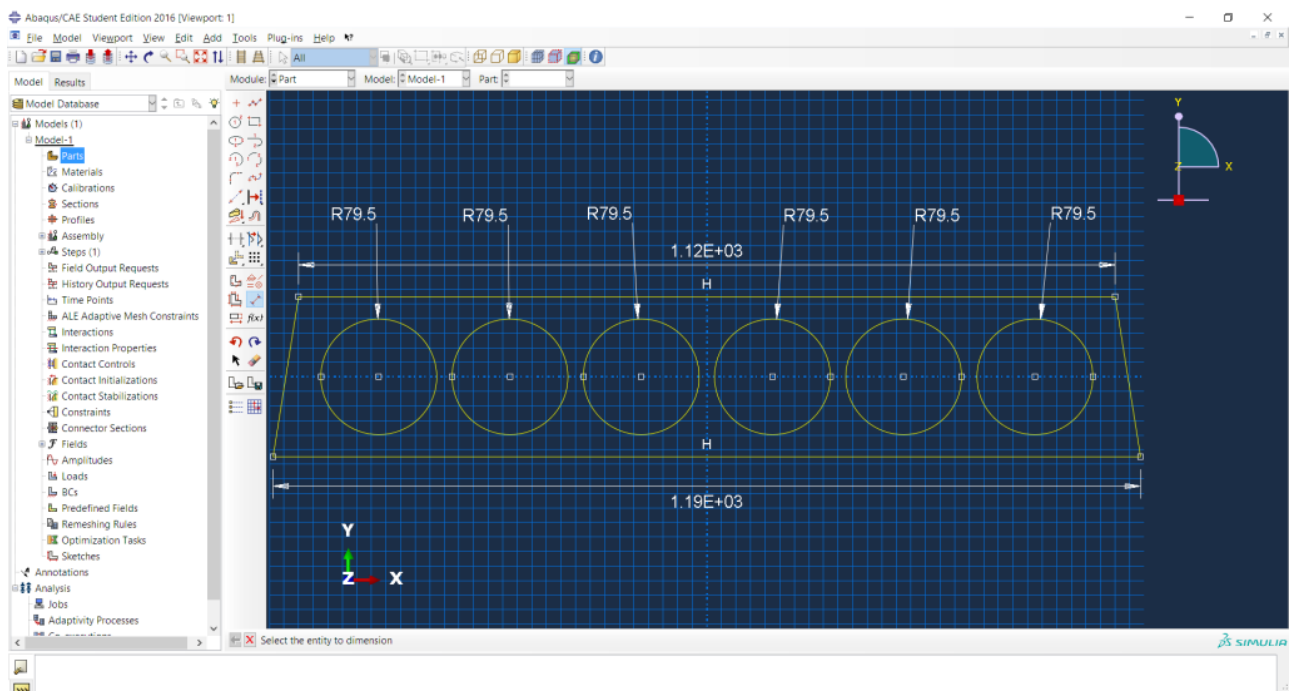

Fig. 2. Pre-processor in ABAQUS.

The calculation process consists of 7 stages, where the task itself, the materials, the geometry of the element, the settings of the finite element grid, the temperature of the faces of the element, the text results and the visualization of the results in the schedule are sequentially set. The fire resistance of the plate was determined by constructing tangents to the curves of deflection at the point of their bending when forming a plastic hinge in the plate $[14,15]$.

The determination of the fire resistance limit of a building or structure as a whole for the limiting state «R» assumes the design calculation as a single nonlinear system. Accounting for physical, geometric and constructive nonlinearities is caused by the necessity of calculating the structure in a state close to the load-bearing capacity and beyond. In this case, neglecting these types of nonlinearities leads to significant errors in the calculation results. Autodesk Revit Structure is software complex is created for designing building structures and coordinating the data with the project. On the basis of Autodesk Revit there are two software modules: tools for building skeletons and further transferring them to structural modules. The collaboration capability used in Autodesk Revit Structure enables all engineers involved in the search to simultaneously access the model of the projected construction site, and also provides tools for virtual division of the model into separate parts with the ability to configure shared access to various parts of the project. The Autodesk Robot Structural Analysis Professional (USA) module provides a two-way link between programs that participate in the work. Thus, the model in the program Autodesk Revit Structure can be automatically updated taking into account the results obtained for further work with the project after the necessary calculations.

There is a special module HYDRA based on the differential equations of Laplace and Poisson in the software complex Sofistik (Germany). The system is divided into finite elements with simplified physical properties. Thermal analysis makes it possible to calculate the temperature distribution within an element in various fire regimes and its different exposure time. It is important to note that the real problem is always spatial, but in Sofistik calculations are performed using only two axes. In practice, Autodesk Revit is used with the finished 3D model as a preprocessor for Sofistik.

It is necessary to set loads, boundary conditions, sections and materials of structural elements and specify all necessary settings for export (finite element grid, finite element size, information about necessary calculations). 
After being exported, the model is presented in a finite-element form. In this case, you can automatically calculate the cross sections of the specified elements. The fire resistance calculation with the HYDRA module can only be performed for individual elements (Fig. 3).
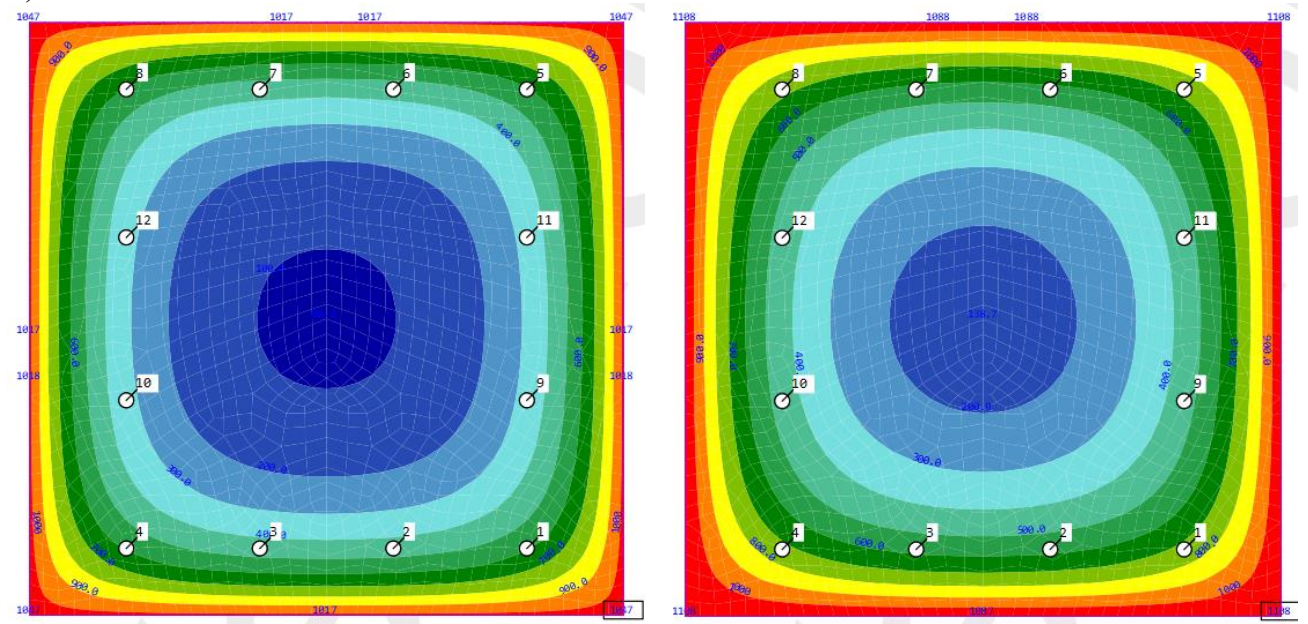

Fig. 3. The heating of element in the report Sofistik (R120 and R150)

The program ELCUT ("Tor" LLC, Russia) allows to solve the construction problems associated with the heating of concrete (Fig.4). The ELCUT also simulates the FEM. For example, using the WinConcret add-in, it is possible to simulate the warm-up of a thinwalled monolithic overlap along the profiled sheet between the brick walls [16-18].

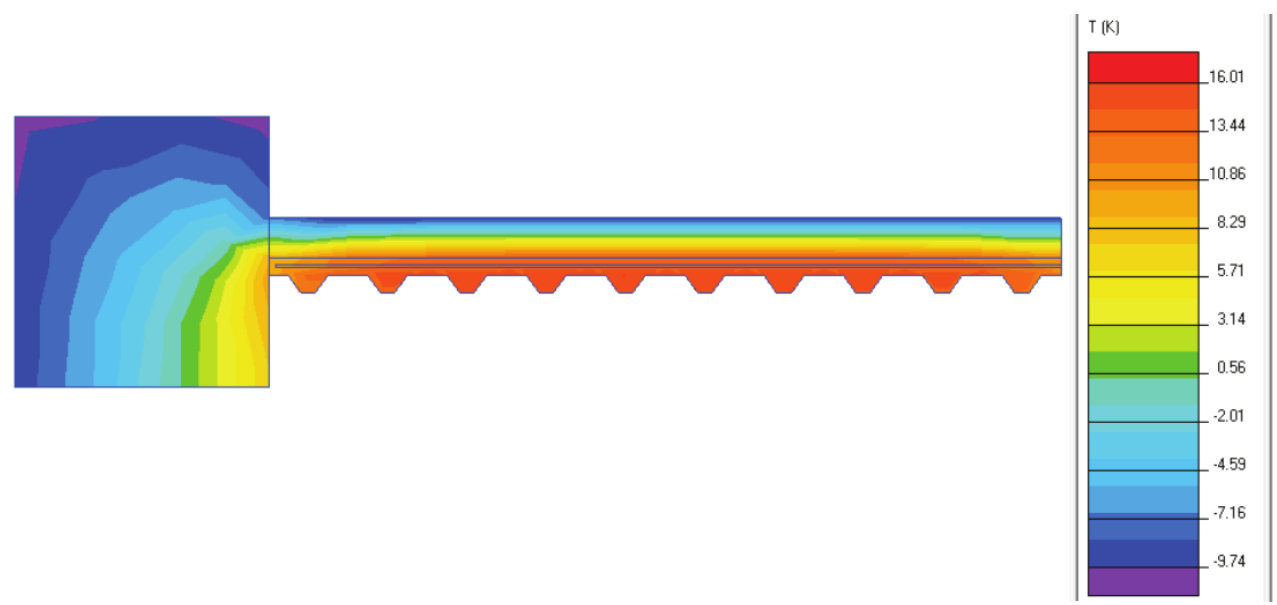

Fig. 4. Model scheme and temperature field based on simulation results in the Elcut [6]

\section{Results and Discussion}

To date, the main method of calculation is the algorithm of the finite element method for each of the modern software systems. Otherwise this method can be called a displacement method. The unknown quantities are the displacements of the finite element system at the characteristic points. These values can be obtained by interpolating the values of the displacement of neighboring nodes. Further, a global stiffness matrix is formed on the basis 
of the finite element scheme and the finite element libraries. Due to this, it is possible to determine the reactions at the nodes of the element as it moves along each of the directions of the degrees of freedom. The system must come to equilibrium to determine the unknowns at each node. A system of linear equations with a significant number of unknowns is being formed. The resulting stresses are transferred from one element to another and the size of the transition is a direct indicator of the quality of the finite element analysis. Table 1 summarizes the analysis of the capabilities of software packages.

Table 1. Advantages and disadvantages of some software complexes for calculating fire resistance.

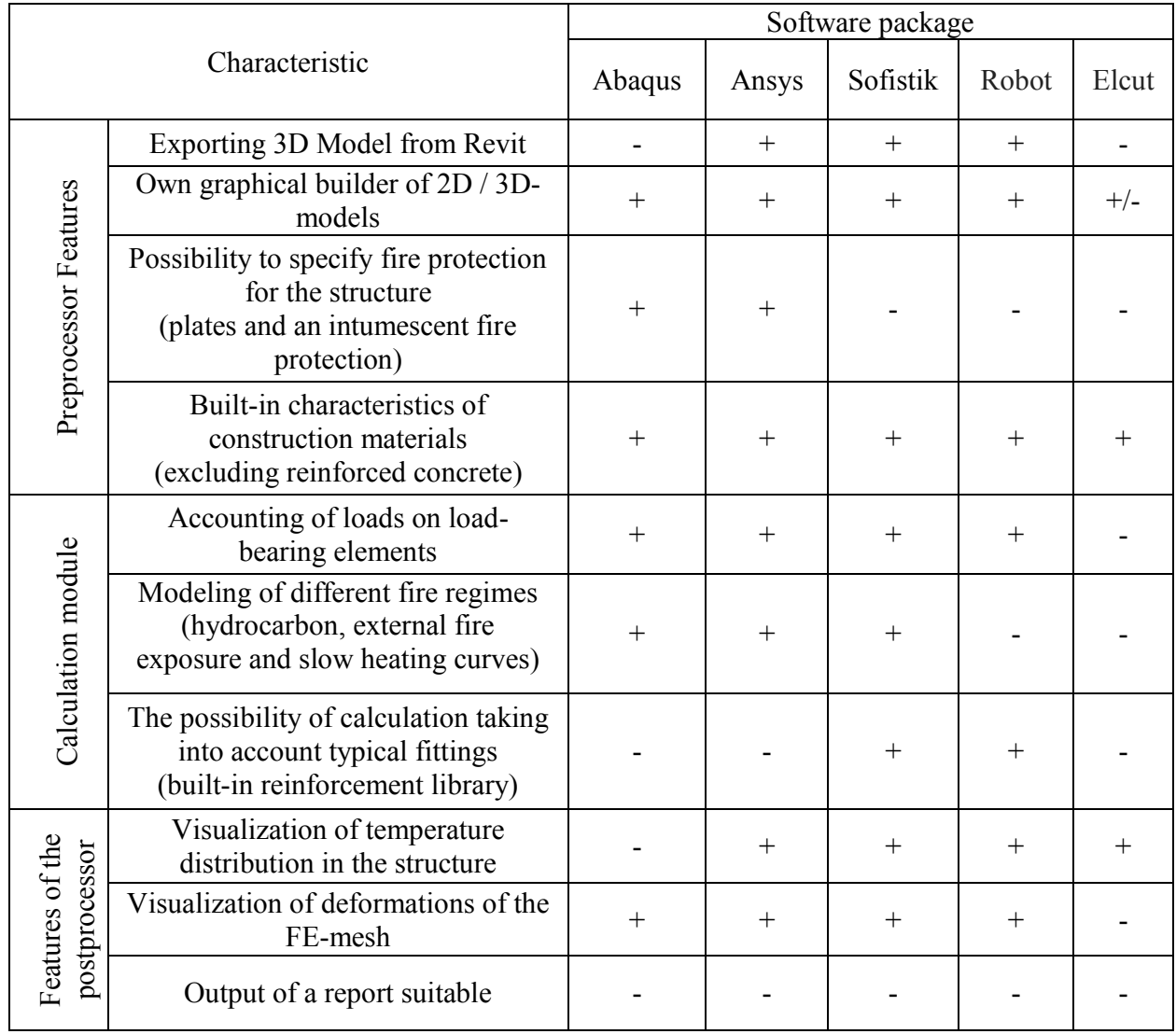

\section{Conclusions}

In some cases, it is advisable to replace expensive full-scale fire resistance tests for computer simulation of the behavior of structures in a fire. The accuracy of modern software systems corresponds to real tests. Also, due to the consideration of various fire factors, software systems can guarantee a high level of proximity to real situations. At the moment there are enough alternatives to calculate the fire resistance of both individual elements and entire structures. The choice of a program primarily depends on the complexity of the user task. The cost of software complexes corresponds to the functionality they contain.

Leader of the possibilities of calculations is ANSYS. This complex has a huge number of functions and tools for modeling full-fledged buildings and simulating a fire in the location given. However, in a number of cases, the modeling of entire structures is 
inexpedient, so the best choice is Sofistik. In the future, it will be possible to observe simplification of the processes of interaction and study software systems. In addition, the trend of development is towards creating a more intuitive interface and the possibility of interaction between programs. This will allow distributing tasks between software complexes and optimize the calculation process. It is also expected to further develop the BIM (building information model) technology and the appearance of a simplified transfer of models from architectural and accounting complexes.

\section{References}

1. A. Krivtcov, M. Gravit, S. Zimin, O. Nedryshkin, V. Pershakov, MATEC Web of Conferences 53, 01032 (2016). DOI: 10.1051/matecconf/20165301032

2. N. Shevchenko, R. Manucharyan, M. Gravit, Y. Geraskin, IOP Conference Series: Earth and Environmental Science 90 (1), 012192 (2017). DOI: 10.1088/17551315/90/1/012192

3. O. Nedryshkin, M. Gravit, K. Grabovyy, MATEC Web of Conferences, 193, 03023 (2018). DOI: $10.1051 /$ matecconf $/ 201819303023$

4. M. Gravit, I. Dmitriev, K. Kuzenkov, MATEC Web of Conferences, 245, 11012 (2018) DOI: $10.1051 /$ matecconf $/ 201824511012$

5. M.R. Garifullin, A.V. Barabash, E.A. Naumova, O.V. Zhuvak, T. Jokinen, M. Heinisuo, Magazine of Civil Engineering 63(3), 53-76 (2016) DOI: 10.5862/MCE.63.4

6. M. Gravit, A. Krivtcov, I. Mingalimov, I. Popovych, Solid State Phenomena, 871, 146-153 (2016). DOI: 10.4028/www.scientific.net/MSF.871.146

7. M. Gravit, I. Dmitriev, A. Ishkov, IOP Conference Series: Earth and Environmental Science 90 (1), 012226 (2017). DOI: 10.1088/1755-1315/90/1/012226

8. E. Nedviga, N. Beresneva, M. Gravit, A. Blagodatskaya, Advances in Intelligent Systems and Computing, 692, 739-749 (2018). DOI: 10.1007/978-3-319-70987-1_78

9. M. Salminen, M. Heinisuo, Journal of Constructional Steel Research 97. 105-113 (2014).

10. P. Kraus, M. Mensingera, F. Tabelingb, P. Schaumann. Structural Fire Engineering 6(4), 237-246 (2015).

11. Organization standard 36554501-006-2006, Rules for ensuring fire resistance and fire safety of reinforced concrete structures.

12. Eurocode EN 1994-2-2009

13. Eurocode EN 1992-1-2:2004

14. A.V. Bardin, O.Yu. Sudar, Construction of Unique Buildings and Structures, 8(35), 36-47 (2015) (rus).

15. M.O. Dudin, N.I. Vatin, Yu.G. Barabanshikov, Magazine of Civil Engineering 2, 33 45 (2015)

16. M.V. Gravit, O.V. Nedryshkin, O.T. Ogidan, Magazine of Civil Engineering 77(1), 38-46 (2018).

17. M. Gravit, O. Zybina, A. Vaititckii, A. Kopytova, Advances in Intelligent Systems and Computing, 692, 1093-1101 (2018). DOI: 10.1007/978-3-319-70987-1_118

18. O.M. Smirnova, Journal of King Saud University-Engineering Sciences, 29(4), 381387 (2017) 